Review

\title{
An Overview on Patient-Centered Clinical Services
}

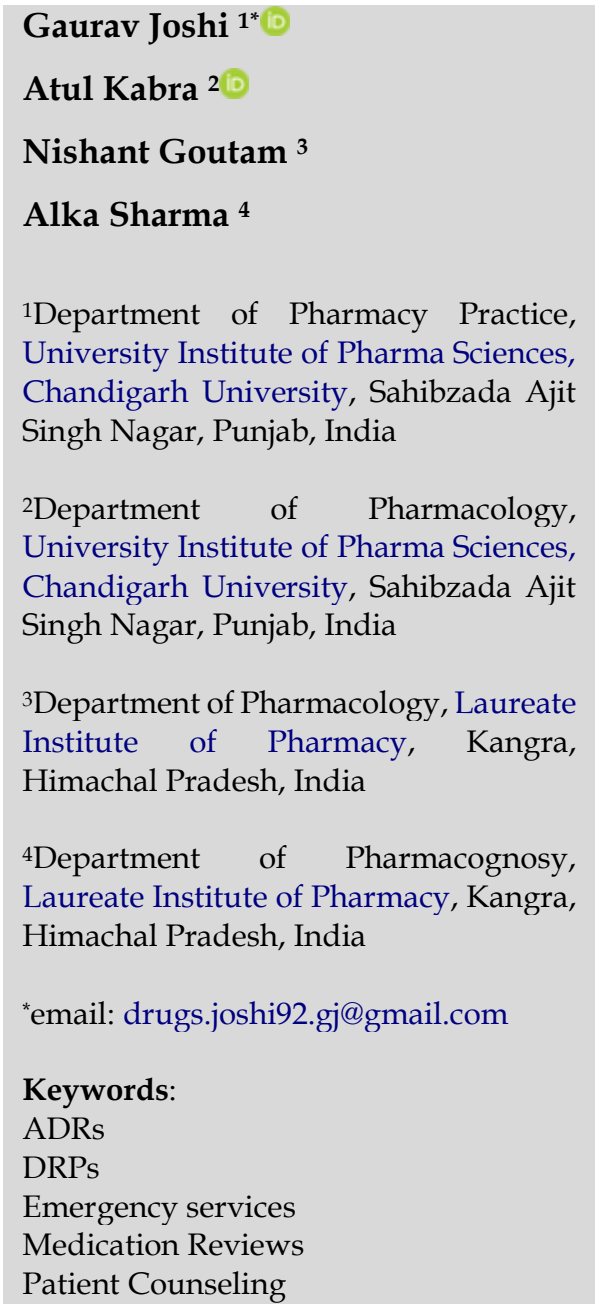

\begin{abstract}
Drug-related problems (DRPs) had often been a concern in the system that needed to be detected, avoided, and addressed as soon as possible. The need for a clinical pharmacist becomes even more important. He is the one who can not only share the load but also be an important part of the system by providing required advice. They fill out the patient's pharmacotherapy reporting form and notify the medical team's head off any drug-related issues. General practitioners register severe adverse drug reactions (ADRs) yearly. As a result of all of this, a clinical pharmacist working in and around the healthcare system is expected to advance the pharmacy industry. Its therapy and drugs can improve one's health quality of life by curing, preventing, or diagnosing a disease, sign, or symptom. The sideshows, on the other hand, do much harm. Because of the services they offer, clinical pharmacy has grown in popularity. To determine the overall effect and benefits of the emergency department (ED) clinical pharmacist, a systematic review of clinical practice and patient outcomes will be needed. A clinical pharmacist's anatomy, toxicology, pharmacology, and medicinal chemistry expertise significantly improves a patient's therapy enforcement. It is now important to examine the failure points of healthcare systems as well as the individuals involved.
\end{abstract}

Received: January $8^{\text {th }}, 2021$

Accepted: March $4^{\text {th }}, 2021$

Published: May 30th, 2021

(C) 2021 Gaurav Joshi, Atul Kabra, Nishant Goutam, Alka Sharma. Published by Institute for Research and Community Services Universitas Muhammadiyah Palangkaraya. This is an Open Access article under the CC-BYSA License (http://creativecommons.org/licenses/by-sa/4.0/). DOI: https://doi.org/10.33084/bjop.v4i2.1978

\section{INTRODUCTION}

Pharmacists are becoming more tired as the workload of dispensing and therapy grows, and the demand-supply goal becomes more difficult. This encourages more pharmacists, who are often active in clinical pharmacy within the healthcare system 1 . The clinical pharmacy's facilities are the primary reason for its increased demand. As a result, it has become an essential and important component of the healthcare system, which is critical in this multidisciplinary setting?2.
Pharmacists play a critical role in patient education and encouragement, as well as advising and engaging with prescribers ${ }^{3}$. Clinical pharmacists bridge the gap between doctors and their patients by having a thorough understanding of medications and treatment plans. As a result, clinical pharmacists and doctors will work together to build a strong pillar for society by providing high-quality patient caret. The presence of a clinical pharmacist in and around healthcare is critical to the pharmacy field's growth 5 . 
It is assumed that a professional person who can treat patients is titled a doctor, physician, clinician, medical practitioner, and others in the present scenario. These people support the medical system and improve the healthcare departments as they have achieved a degree in medical or allied health ${ }^{6}$. A system like this is critical for any country's growth. These individuals are regarded as the best because they lead a healthcare system that is constantly in need of perfection and change 7 . Thus, the necessity for a clinical pharmacist also becomes crucial. They are the ones who not only share the load but often be a responsible part of the system for their advice which is needed to be a cure, treats or even save a life'. This review will discuss several things related to the role of clinical pharmacists in patient-oriented pharmaceutical services, including various activities undertaken, such as medication reviews, counseling, therapeutic drug monitoring, and adverse drug reactions that may occur due to negligence in pharmaceutical care, as well as the expected outcomes of patient-centered clinical services.

\section{DRUG-RELATED PROBLEMS}

Drug-related problems (DRPs) have often been a systemic concern that must be recognized, avoided, and handled as soon as possible. Any cure for the problem isn't new ${ }^{8}$. Different terms are proposed; for instance, 'drug-treatment issue' is regularly utilized as well, and this term was presented by Cipolle et $a l^{9}$. Krska ${ }^{10}$ proposed the term 'Drug Care Issue' in 2002. This is regularly utilized in the UK. Pharmacotherapy disappointment compares to negative clinical results coming about because of the usage or the absence of meds ${ }^{11}$.

Various reports have come forward which enlists "druginduced problem" since many efforts have been put forward to optimize the rational usage of the drug and medical preparations ${ }^{12}$. In such cases, a variety of factors can play a crucial role, like social pressure on the physician, the law and system of healthcare services, and the marketing strategies of pharmaceuticals, plus the patient itself play an essential role in this system. Polypharmacy and increased drugs use are two factors that contribute to problems that defy pharmacotherapeutic concepts. Such issues are then categorized as DRPs ${ }^{13,14}$. Niriayo et al. ${ }^{15}$ describe the points included in the DRPs based on Cipolle's method as presented in Table I.

Table I. Category of DRPs

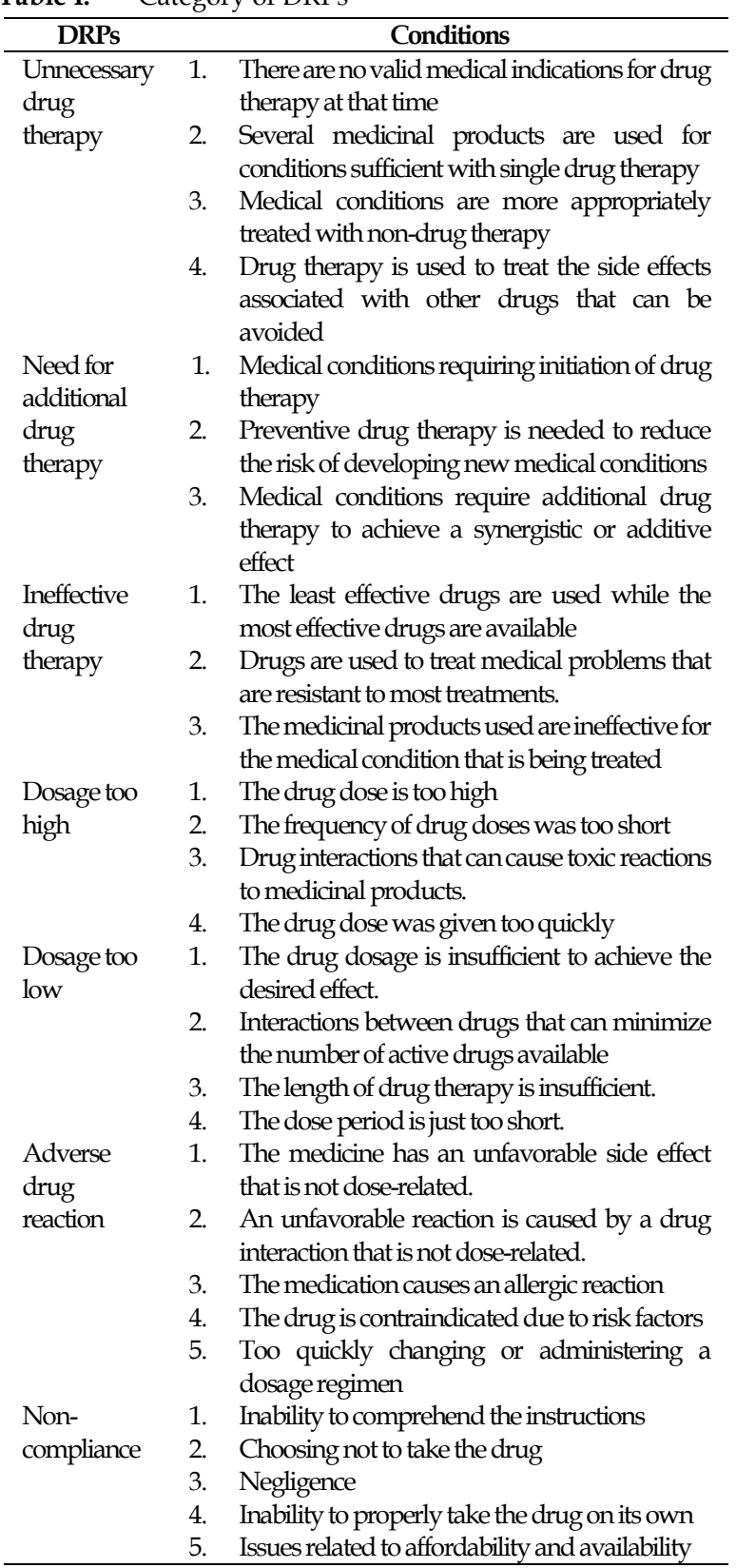




\section{MEDICATION ERROR}

Many therapies and medications have been involved that cure, prevent, or diagnose a disease, sign, or symptom to enhance the standard of life in health. However, improper usage of those drugs can cause severe damage by creating new adverse situations, be it morbidity or mortality ${ }^{16}$. From 1.5 to $35 \%$, errors related to medication were reported to the patients under hospitalization, and DRPs were seen to be common. Around $6.5 \%$ of morbidity and mortality rates of these errors were considered liable for costs of hospitalized persons, and It was discovered that two-thirds of these incidents could have been avoided ${ }^{17}$. To reduce the potential risk of these errors, pharmaceutical care provided by clinical pharmacists in the hospital setting allows multiple layers of patient protection ${ }^{18}$.

Although few reports have uttered the improvement in medication error management by involving clinical pharmacists, there is insufficient knowledge in some of the developing countries ${ }^{19}$, such as Iran. A clinical drug store residency program was begun in the year 1994 in Iran, and till now, almost 100 clinical drug specialists got earned their diplomas. A large portion of them was the academic staff and was occupied with the clinical treatment group in the instructing clinics. Drug audit by the drug specialists in the emergency clinic setting is in advancement because of the association of clinical drug specialists on the medical care group in the irresistible sicknesses ward of Imam Hospital, Tehran, Iran ${ }^{20}$.

Pharmacists are expected to review medical charts as part of their normal duties. They reported pharmacotherapy monitoring, and all the reports of drug problems were submitted to the head of the medical team ${ }^{21}$. To optimize the result in a complex situation, it must possess an emergency system, diagnostic procedure, sufficient clinical therapy, availability of antidotes, supportive services, and the best knowledge for managing the clinical cases. A multidisciplinary team gives more results than a monodisciplinary way ${ }^{2,23}$. Hospital pharmacy and pharmacists have got a synonymous role here.

\section{CLINICAL PHARMACY AT EMERGENCY DEPARTMENT}

For assessing the efficacy and safety of a particular medication combination of the knowledge of pharmaceutics, pharmacokinetics, pharmacodynamics, and therapeutic drug monitoring (TDM) is required in various clinical settings ${ }^{24}$. The development of modern analytical techniques has made the determination of pharmacokinetic parameters easier by measuring the concentration of drugs in the blood. Such parameters give necessary information about a medicament by assessing it clinically ${ }^{25}$. As a result, TDM is a method that aids a medical practitioner in providing a patient with a safe and successful care. Next, good monitoring from medical practitioner can confirm plasma-drug concentration above or below in the therapeutic range ${ }^{26}$. Adverse drug reactions (ADRs) are life-threatening situations. This imparts a negative effect on the standard of life and strives significant expenses on the healthcare systems $^{27,28}$. In the United States, the fourth cause of death rate is $\mathrm{ADRs}^{29}$. The death rates are much higher due to medication errors and ADRs than the death caused by any highway accident, cancers, or AIDS, stated by recent data ${ }^{30}$. Moreover, it has been reported that around $7 \%$ of hospitalizations are the results of ADRs ${ }^{2931,32}$.

\section{THE ROLE OF CLINICAL PHARMACISTS}

In the patient-oriented era, the clinical pharmacist is defined as a discipline that focuses on improving the efficacy and rationality of drugs and minimizing drug toxicity in patients based on pharmaceutical care. In general, patient-oriented clinical pharmacists' role 
includes medication reviews, providing counseling, therapeutic drug monitoring, and ADRs monitoring 33,34 , as illustrated in Figure 1. In addition, clinical pharmacists also have other roles, such as identifying drug-related problems, promoting and recommending medication fulfillment, reviewing treatment data and medical history, examining medication errors including drug prescriptions, dispensing errors and drug administration, identifying drug interactions, suggest individual dosages, provide patient consultations, and more $35-39$. Clinical pharmacy services are not limited to the activities mentioned above, in which clinical pharmacists can also carry out an expanded role such as conducting complete interviews with patients or their families about patient history such as medical, social, allergies, use of OTC drugs, dietary supplements, and alternative medicine ${ }^{4,40}$.

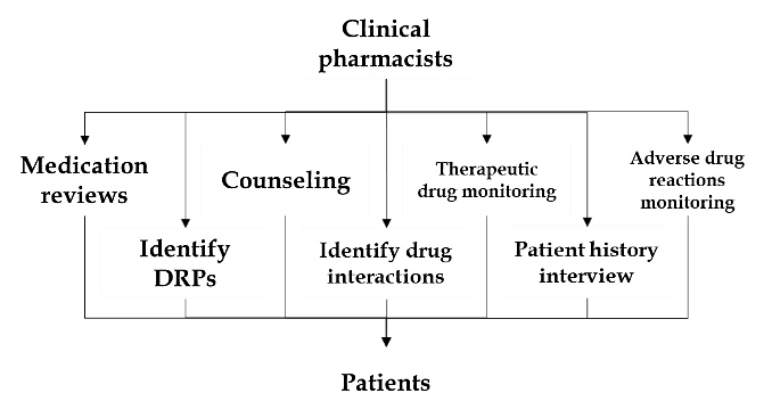

Figure 1. The role of the patient-centered clinical pharmacists

\section{MEDICATION REVIEW}

In terms of patient care and safety, medication-related errors are quite frequent and are an important factor that should be given extra attention. As a result, it is important to pay attention to the weak points of healthcare systems as well as the patients involved ${ }^{41}$. Pharmacist intervention is useful in promoting proper therapy compliance, interviewing patients, reconciling prescriptions, and advising patients for proper followup, according to findings from different studies ${ }^{4243}$. Hence, clinical pharmacists are mandatory to participate actively as a member of the healthcare team and teach. Their fundamental responsibility is to check on drug therapy, review patient(s) medical records, attend ward rounds, and educate health care workers about disease management pharmacologically and nonpharmacologically ${ }^{44}$. These outcomes of the drug therapy care given by clinical pharmacists are fresh to the hospitals. Infectious diseases may be spread through medication errors. The number of errors varies depending on the patient's demographics, as well as his or her illness and drug background, both past and current 45 .

Another related research drew attention to drug mistakes by putting them in the context of patients' problems ${ }^{46}$. Drug dosing and therapy choice problems can cause most errors - reasons for medication errors in a pediatric surgical ward may be due to improper dose adjustment to that patient ${ }^{47}$. The qualities of drug blunders during the organization period of the medicine use measure were contemplated. Out of the relative multitude of preeminent basic mistakes should be oversight blunders, blunders of the wrong portion of medication, and wrong time ${ }^{48}$.

The high chance and event of drug mistake could likewise be because of paper-based requests in clinical history alongside automated enlistment of medicine, inaccessibility of the clinical record for drug specialists in the medical clinic drug store, tolerant over-burden in a showing clinic, and therefore working over-burden of doctor and attendants as well as inaccessibility or absence of therapy guidelines ${ }^{49-51}$. The reason for contrasts between frequencies of meds blunders is prescription blunders, the precision of information assortment technique, and revealing framework. Furthermore, the degree of polished methodology, individual execution, and individual social abilities of the elaborate medical services laborers may impact the term and kind of the 
prescription mistake ${ }^{52}$. Intercessions of clinical drug specialists inside the entire treatment measure, starting from apportioning to the organization to the patient, can limit the odds of medicine mistakes and be advantageous to tolerant care. This accomplishment is simply due to the contribution of clinical drug specialists in unique prescription ward adjusts and noticing and breaking down various strides of drug care ${ }^{53}$. Thus, the principal part of crisis division drug specialists is to lessen possibly hurtful medicine mistakes brought about by any factor ${ }^{54}$. For the medicine mistakes, it has been discovered that patients more than 50 years of age, male sex, and quantities of controlled medications had no huge impacts except that non-antitoxin drug classes probably show hazard factor identified with a quiet segment or illness and treatment ${ }^{55,56}$. Even though the connection between the recurrence of prescription mistakes and quantities of regulated medications has not found as a danger factor. Medical service workers are included as therapy and patient care groups in providing instructions to emergency clinics to reduce prescription errors ${ }^{57}$. Horribleness, death rate, and cost of patient consideration get influenced by medicine errors. Most of the prescription mistakes were distinguished, detailed, and introduced in the beginning stage of medication treatment by clinical drug specialists ${ }^{58}$.

\section{DRUG-RELATED}

PROBLEMS

\section{IDENTIFICATION}

It is well recognized that taking an excessive number of drugs can lead to a person being admitted to the hospital, either directly or indirectly. According to the Pharmaceutical Care Network Europe (PCNE), DRPs are characterized as an occasion or situation, including drug treatment that really or possibly meddles with the ideal wellbeing outcomes ${ }^{17}$. Some DRPs like prescription blunders and unfriendly medication responses are truly basic on account of hospitalized patients and may cause patients some dreariness or mortality ${ }^{59}$. There are a few characterization frameworks for DRPs; some are by Strand et al.60, an agreement bunch in Granada, the $\mathrm{PCNE}^{61}$, and Apoteket $\mathrm{AB}$ (National Corporation of Pharmacies in Sweden) ${ }^{62}$. Drug-related problems can be experienced throughout the entire medication process and perhaps tell you all the risk factors for adverse drug reactions and events. In recent years, drug-induced morbidity has often been related to adverse drug reactions; still, these occupy a small portion of DRPs63.

Clinical drug specialists are assigned specialists who can co-relate determination, research center qualities, clinical history, and solutions with the progressing treatment of an individual patient ${ }^{64}$. Thus, the presence of a clinical drug specialist is essential so he can distinguish and tackle a few DRPs more effectively than a fake framework can, for example, Computerized Physician Order Entry frameworks (CPOE) or Clinical Decision Support System (CDSS). Many investigations have detailed that a clinical drug specialist is crucial, which offers better assistance for persistent consideration and wellbeing 65,66 .

In one study, the contingency of DRPs was correlated with age, gender, polypharmacy, and several comorbidities. An identical study was done, in which correlation of variables like age, gender and polypharmacy was established with an increase in $\operatorname{DRPs}^{67,68}$. The research was carried out that stresses the role in identifying, assessing, and preventing DRPs in elderly patients. They also focused on polypharmacy (six or more concomitantly) leading to DRPs ${ }^{69}$. The factors leading to DRPs were polypharmacy, comorbidities, and patient age reported by a study. As far as age-related DRPs are concerned, most patients were in the geriatric age group; a maximum number of DRPs were seen in this group. Maximum numbers of medicines were 
prescribed in this group, i.e., approximately an average of 10 to 15 drugs per patient. The number of DRPs and medications prescribed is eventually increased depending on the patient's illness or disease, which was accompanied by an increase in the age range of patients ${ }^{70,71}$.

Moreover, this leads to an increase in the age group, which shows a rise in the number of comorbid conditions, which is the highest amongst the other population groups. Multiple comorbid conditions, polypharmacy, inadequate knowledge about the disease, and others can be the reason behind it. The correlation coefficient of age v/s DRPs was 0.13 , indicating a positive correlation between the two variables ${ }^{72}$. Chances of DRPs increase with the rise in age. With the increase in DRPs, age development, comorbid conditions increase, and as a result, the number of drugs prescribed increases ${ }^{73}$. The leading cause of DRPs is considered to be polypharmacy. Drug-drug interaction is the main reason for a positive correlation between the numbers of drugs prescribed and DRPs ${ }^{74}$.

Maximum of major and significant drug-drug interactions was recognized in this age bunch, out of which few were intentional $\backslash$ beneficial. Drug-drug interactions can lead to a decrease or increase in a drug's effect, eventually causing a sub-therapeutic or supratherapeutic dose ${ }^{75}$. Thus, to reduce the occurrence of drug-drug interactions, pharmacokinetics and pharmacodynamic properties of drugs should be kept in mind as DRPs are mostly dependent on chemical as well as physical properties of the drug and, as a consequence, are often more difficult to influence and prevent ${ }^{76}$. Various methods have been proposed to prevent drug interactions and made to work. Firstly, the pharmacokinetic properties of each drug are observed. If found any discrepancy such as the half-life of the drug is not crossed, then the administration timing can be varied and changed accordingly ${ }^{\pi}$. The following method is to provide an alternate therapy plan to a patient. Such interactions are notable and are needed to be checked and monitored often. For such instances, an alternate therapy plan works well by minimizing interactions with substituting medications for their counterparts. When these plans are carried out and implemented, the medication reactions are better presented, and the patient receives the best care possible ${ }^{78}$.

\section{THERAPEUTIC DRUG MONITORING}

Therapeutic drug monitoring is a branch of the clinical chemist in which data is determined by a clinician, how a patient responds to a specific therapy and the factors that influence that response. When a therapy fails due to a patient's insufficient reaction, quantitative examination of plasma levels will show who is truly following the instructions and who is not ${ }^{26}$. The approach also provides data on individual reactions to drug use habits and changes in drug usage as a result of the altered physiological condition. A critical point of TDM is to seek out the dose-response relationship, its affectivity, rationale, and others ${ }^{51}$. This TDM is much acceptable and needed for a few categories of drugs when value and quality of life are considered. Such a category may be noted by public bodies and regulatory agencies for TDM to be carried out. The reality of TDM is that it is based on estimating drug concentrations in body fluids like saliva, plasma, serum, and others ${ }^{79}$.

Except for drugs that do not follow the dose-response relationship or facts such as individual variations, particular variations, or ethnic variations, the TDM is also very effective in delivering a beneficial service if the medication has a dose-response relationship ${ }^{80}$. Reporting blood concentrations can be of no use or may even make treatment more difficult. The TDM assay must be performed for both the administered drugs and their 
metabolite for particular drug groups where the metabolite is also active. The use of therapeutically low concentrations of drugs in fewer patients than the normal dose has been shown to be highly successful ${ }^{81}$. In a few patients, a higher concentration than the normal range of serum concentration is needed without causing any harmful effects and yielding a satisfactory result. However, such circumstances may indicate that higher doses are toxic concentrations, causing undesirable anxiety and necessitating a dose reduction. One must consult the physician and clinical pharmacist to urge a better conclusion by approaching a team discussion 82,83 . Therapeutic drug monitoring is the best option required for critical conditions and requires emergency support. The reports should be made available within a short duration to make TDM very effective ${ }^{84}$. Therapeutic drug monitoring can also be helpful for neonates and pregnant ladies. During pregnancy, physiological changes are expected, like increased renal function, increased cardiac output, increased placental blood flow, variations in the concentration of plasma proteins, hormonal changes, and others ${ }^{85}$. Since drugs are administered to sustain and promote good health and ill conditions throughout pregnancy, these drugs may be capable of crossing the placental barrier and causing toxic effects on the fetus, TDM is needed. This method is also crucial for neonates during their treatment, but many issues are also observed $^{86}$. Many medications, for example, must be started right away without any prior knowledge of the neonate's clinical history. Drugs are appreciated more than their adverse effects, such as jaundice, in such situations. The issues that can cause some alteration in TDM of neonates can be the cluster of samples, correct administration of drugs, their response to drugs, the presence of drugs in the body that are received through the placenta, or the exposure of the body to drugs in the fetus. In such cases, the clinical team's combined effort will have further advantages and justification ${ }^{87,88}$.

The medication level assessment in body fluids must be cost-effective in terms of expenses. The expenditure of operating a specific test is directed by the summation of equipment, personnel, supply, and overall expenditure for particular time duration and dividing that amount by the number of analytical tests performed in the same duration 89,90 . The overall charges are then calculated by multiplying the desired benefit by the expense of the test. The use of clinical pharmacokinetics by therapeutic drug monitoring services was considered to reduce adverse reactions, reduce intensive care unit length of stay, and shorter overall hospital care costs ${ }^{26}$.

As mentioned earlier, TDM can appear to be of less benefit in certain countries, but when special therapies are taken into account, it proves to be extremely valuable in terms of delivering effective service. When the failure of a therapy or harmful effects is considered, this method rises as a powerful tool used in the treatment. It necessitates the use of pharmaceutical, pharmacokinetic, and pharmacodynamic techniques in tandem ${ }^{91}$. The system's proper operation necessitates a simple calculation of the drug level in the blood and reference to the normal range. It also increases a drug's protection and efficacy in a specific person; additionally, it helps identify noncompliant patients' problems ${ }^{92}$. The time of sample collection after dose administration, the dosage history, the patient's response, and the desired clinical goals all play a role in providing patient-centered disease management ${ }^{93}$.

\section{ADVERSE DRUG REACTIONS}

One study found that after education and the establishment of Pharmacovigilance Committees in hospitals, there was a substantial increase in ADR reporting. It is engrossing that despite sending the 
documents, posters, and pamphlets of the Iranian Adverse Drug Reactions Monitoring Center (IADRMC) since 2004, the number of ADRs was deficient from 2004 until 2007. Despite the fact that the author saw a rise in the number of ADRs after 2007, an essential aspect of the experience was that the frequency of reports was not as good as it should have been ${ }^{94,95}$.

The lack of awareness of the national center, the absence of serious drug reactions, and skepticism about the causality relationship between the reaction and suspected drug were all stated as major reasons in the report ${ }^{96}$. Pharmacists and nurses were proposed for similar reasons. It was stated from the above studies that the top cause of ADRs were antibiotics approximately $45.5 \%$. Moreover, ceftriaxone was the most common antibiotic linked to ADRs, with side effects such as rash, hives, and anaphylactic shock ${ }^{97}$. Technically, high levels of antibiotic-associated ADRs are frequently linked to high drug use, both within and outside the world. More than half of all patients who take antibiotics see a doctor, and this number rises to $59 \%$ for general practitioners ${ }^{98}$. Adverse drug reactions are more reported in nurses as compared to physicians and pharmacists. Due to the close contact with both the physicians and the patients and management of drug administration of those patients, it is counted as the leading cause ${ }^{99}$. Until 2002, the nurses in England were not allowed to fill out yellow cards. The role of nurses in the pharmacovigilance system was demonstrated by relating all previous studies and experience ${ }^{100}$. At least one injectable drug is used in $45 \%$ of prescriptions. By avoiding needless injections, such ADRs can be avoided. Since injectables are not often needed for successful outcomes, and because of the higher costs and serious and immediate adverse reactions, oral drugs are likely to be preferred wherever possible to minimize the highest risk of injectable $\mathrm{ADRs}^{101,102}$

\section{CONCLUSION}

Clinical pharmacists play an important role in the crisis center, which is continuously evolving. Other medical care laborers claim additional time from clinical pharmacists to be given to the office to offer fundamental types of assistance. Experienced clinical pharmacists can assist with calming tension on other staff and give compelling patient consideration. Nevertheless, a proper investigation of clinical practice and patient results would be needed to survey the general effect and advantages. Clinical pharmacists are recognized patient consideration advantage by working together with doctors or wellbeing frameworks. This enables them to participate in dynamic treatment exercises as part of the patient's care services team, assisting in the rational use of drugs for patient safety and improving long-term consideration. The executives' findings assume liability for threat factors related to treatment and reduce medical care expenses based on their level of consideration and illness. Therefore, clinical pharmacists are a resource for the health care team and patients.

\section{ACKNOWLEDGMENT}

We want to express our sincere gratitude to Dr. Saahil Arora, Professor, and Director, UIPS, Chandigarh University, Gharuan, Mohali, Punjab. This review did not receive any specific grant from funding agencies.

\section{AUTHORS' CONTRIBUTION}

Gaurav Joshi: conceptualization, investigation, writing original draft. Atul Kabra: methodology, visualization. Nishant Goutam: writing - review \& editing. Alka Sharma: writing - review \& editing.

\section{DATA AVAILABILITY}

None. 


\section{CONFLICT OF INTEREST}

The author has no conflicts of interest to declare.

\section{REFERENCES}

1. Dalton K, ByrneS. Role of the pharmacist in reducing healthcare costs: current insights. Integr Pharm Res Pract. 2017;6:37-46. doi:10.2147/IPRP.S108047

2. Tegegn HG, Abdela OA, Mekuria AB, Bhagavathula AS, Ayele AA. Challenges and opportunities of clinical pharmacy services in Ethiopia: A qualitative study from healthcare practitioners' perspective. Pharm Pract. 2018;16(1):1121. doi:10.18549/PharmPract.2018.01.1121

3. Visacri MB, Figueiredo IV, Lima TdM. Role of pharmacist during the COVID-19 pandemic: A scoping review. Res Social Adm Pharm. 2021;17(1):1799-806.

doi:10.1016/j.sapharm.2020.07.003

4. Francis J, Abraham S. Clinical pharmacists: Bridging the gap between patients and physicians. Saudi Pharm J. 2014;22(6):600-2. doi:10.1016/j.jsps.2014.02.011

5. Tahniyath F. Clinical Pharmacist- A Need for the Society. Indian J Pharm Pract. 2017;10(1):59-61. doi:10.5530/ijopp.10.1.12

6. Kruk ME, Gage AD, Arsenault $C$, Jordan $K$, Leslie $\mathrm{HH}$, Roder-DeWan S, et al. High-quality health systems in the Sustainable Development Goals era: time for a revolution. Lancet Glob Health. 2018;6(11):e1196-e1252. doi:10.1016/s2214$109 x(18) 30386-3$

7. Thimbleby H. Technology and the Future of Healthcare. J Public Health Res. 2013;2(3):e28. doi:10.4081/jphr.2013.e28

8. Lim XY, Yeo QQ, Kng GLL, Chung WL, Yap KZ. Validation of a Drug-Related Problem Classification System for the Intermediate and Long-Term Care Setting in Singapore. Pharmacy. 2018;6(4):109. doi:10.3390/pharmacy6040109

9. Cipolle R, Strand LM, Morley PC. Pharmaceutical Care Practice. the clinician's Guide, $3^{\text {rd }}$ Edition. New York, NY: McGraw Hill; 2012.

10. Krska J, Cromarty JA, Arris F, Jamieson D, Hansford $D$, Duffus PR, etal. Pharmacist-led medication review in patients over 65: a randomized, controlled trial in primary care. Age Ageing. 2001;30(3):205-11. doi:10.1093/ageing/30.3.205

11. Shiovitz TM, Bain EE, McCann DJ, Skolnick P, Laughren T, Hanina A, et al. Mitigating the Effects of Nonadherence in Clinical Trials. J Clin Pharmacol. 2016;56(9):1151-64. doi:10.1002/jcph.689

12. Ofori-Asenso R, Agyeman AA. Irrational Use of Medicines-A Summary of Key Concepts. Pharmacy. 2016;4(4):35. doi:10.3390/pharmacy4040035

13. Denis JL, van Gestel N. Medical doctors in healthcare leadership: theoretical and practical challenges. BMC Health Serv Res. 2016;16(Suppl 2):158. doi:10.1186/s12913-016-1392-8

14. Salmond SW, Echevarria M. Healthcare Transformation and Changing Roles for Nursing. Orthop Nurs. 2017;36(1):12-25. doi:10.1097/NOR.0000000000000308

15. Niriayo YL, Kumela K, Kassa TD, Angamo MT. Drug therapy problems and contributing factors in the management of heart failure patients in Jimma University Specialized Hospital, Southwest Ethiopia. PLoS One. 2018;13(10):e0206120. doi:10.1371/journal.pone.0206120

16. Khalil H, Huang C. Adverse drug reactions in primary care: a scoping review. BMC Health Serv Res. 2020;20(1):5. doi:10.1186/s12913-019-4651-7

17. Movva R, Jampani A, Nathani J, Pinnamaneni SH, Challa SR. A prospective study of incidence of medication-related problems in general medicine ward of a tertiary care hospital. J Adv Pharm Technol Res. 2015;6(4):190-4. doi:10.4103/2231-4040.166502

18. Hua XL, Gu M, Zeng F, Hu H, Zhou T, Zhang Y, etal. Pharmacy administration and pharmaceutical care practice in a module hospital during the COVID-19 epidemic. J Am Pharm Assoc. 2020;60(3):431-8.ei. doi:10.1016/j.japh.2020.04.006

19. Chalasani SH, Ramesh M, Gurumurthy P. Pharmacist-Initiated Medication Error-Reporting and Monitoring Programme in a Developing Country Scenario. Pharmacy. 2018;6(4):133. doi:10.3390/pharmacy6040133

20. Noormandi A, Karimzadeh I, Mirjalili M, Khalili H. Clinical and economic impacts of clinical pharmacists' interventions in Iran: a systematic 
review. DARU J Pharm Sci. 2019;27:361-78. doi:10.1007/s40199-019-00245-8

21. Jafarian K, Allameh Z, Memarzadeh M, Saffaei A, Peymani P, Sabzghabaee AM. The Responsibility of Clinical Pharmacists for the Safety of Medication Use in Hospitalized Children: A Middle Eastern Experience. J Res Pharm Pract. 2019;8(2):83-91. doi:10.4103/jrpp.JRPP_19_66

22. Taberna M, Moncayo FG, Jané-Salas E, Antonio M, Arribas L, Vilajosana E, et al. The Multidisciplinary Team (MDT) Approach and Quality of Care. Front Oncol. 2020;10:85. doi:10.3389/fonc.2020.00085

23. Haines A, Perkins E, Evans EA, McCabe R. Multidisciplinary team functioning and decision making within forensic mental health. Ment Health Rev. 2018;23(3):185-96. doi:10.1108/MHRJ-01-20180001

24. Shipkova M, Christians U. Improving therapeutic decisions: Pharmacodynamic monitoring as an integral part of Therapeutic Drug Monitoring. Ther Drug Monit. 2019;41(2):111-4. doi:10.1097/FTD.0000000000000627

25. Buclin T, Thoma Y, Widmer N, André P, Guidi M, Csajka C, et al. The Steps to Therapeutic Drug Monitoring: A Structured Approach Illustrated With Imatinib. Front Pharmacol. 2020;11:177. doi:10.3389/fphar.2020.00177

26. Kang JS, Lee MH. Overview of Therapeutic Drug Monitoring. Korean J Intern Med. 2009;24(1):1-10. doi:10.3904/kjim.2009.24.1.1

27. Coleman JJ, Pontefract SK. Adverse drug reactions. Clin Med. 2016;16(5):481-5. doi:10.7861/clinmedicine.16-5-481

28. ShamimS, SharibSM, Malhi SM, MuntahaS, Raza H, AtaS, et al. Adverse drug reactions (ADRS) reporting: awareness and reasons of under-reporting among health care professionals, a challenge for pharmacists. Springerplus. 2016;5(1):1778. doi:10.1186/s40064-016$3337-4$

29. Wasserfallen JB, Livio F, Buclin T, Tillet L, Yersin B, Biollaz J. Rate, type, and cost of adverse drug reactions in emergency department admissions. Eur J Intern Med. 2001;12(5):442-7. doi:10.1016/s09536205(01)00159-5

30. Lazarou J, Pomeranz BH, Corey PN. Incidence of adverse drug reactions in hospitalized patients: a meta-analysis of prospective studies. JAMA. 1998;279(15):1200-5. doi:10.1001/jama.279.15.1200

31. Pirmohamed M, James S, Meakin S, Green C, Scott AK, Walley TJ, et al. Adverse drug reactions as cause of admission to hospital: prospective analysis of 18 820 patients. BMJ. 2004;329(7456):15-9. doi:10.1136/bmj.329.7456.15

32. Courtman BJ, Stalling SB. Characterization of drugrelated problems in elderly patients on admission to a medical ward. Can J Hosp Pharm. 1995;48(3):161-6.

33. Sanii Y, Torkamandi H, Gholami K, Hadavand N, Javadi M. Role of pharmacist counseling in pharmacotherapy quality improvement. J Res Pharm Pract. 2016;5(2):132-7. doi:10.4103/2279-042X.179580

34. Hepler CD. Clinical pharmacy, pharmaceutical care, and the quality of drug therapy. Pharmacotherapy. 2004;24(11):1491-8. doi:10.1592/phco.24.16.1491.50950

35. Elden NMK, Ismail A. The Importance of Medication Errors Reporting in Improving the Quality of Clinical Care Services. Glob J Health Sci. 2016;8(8):243-251. doi:10.5539/gjhs.v8n8p243

36. Viktil KK, Blix HS. The impact of clinical pharmacists on drug-related problems and clinical outcomes. Basic Clin Pharmacol Toxicol. 2008;102(3):275-80. doi:10.1111/j.1742-7843.2007.00206.x

37. Tasaka Y, Tanaka A, Yasunaga D, Asakawa T, Araki H, Tanaka M. Potential drug-related problems detected by routine pharmaceutical interventions: safety and economic contributions made by hospital pharmacists in Japan. J Pharm Health Care Sci. 2018;4:33. doi:10.1186/s40780-018-0125-z

38. Bragazzi NL, Mansour M, Bonsignore A, Ciliberti R. The Role of Hospital and Community Pharmacists in the Management of COVID-19: Towards an Expanded Definition of the Roles, Responsibilities, and Duties of the Pharmacist. Pharmacy. 2020;8(3):140. doi:10.3390/pharmacy8030140

39. Alsairafi Z, Waheedi M, Alsaleh F. The perspectives of patients and physicians on the role of pharmacists in improving medication adherence in type 2 diabetes: a qualitative study. Patient Prefer Adherence. 2019;13:1527-43. doi:10.2147/PPA.S218068

40. Vinterflod C, Gustafsson M, Mattsson S, Gallego G. Physicians' perspectives on clinical pharmacy 
services in Northern Sweden: a qualitative study. BMC Health Serv Res. 2018;18:35. doi:10.1186/s12913-018-2841-3

41. da Silva BA, Krishnamurthy M. The alarming reality of medication error: a patient case and review of Pennsylvania and National data. J Community Hosp Intern Med Perspect. 2016;6(4):31758. doi:10.3402/jchimp.v6.31758

42. Abousheishaa AA, Sulaiman AH, Huri HZ, Zaini S, Othman NA, Aladdin Zb, et al. Global Scope of Hospital Pharmacy Practice: A Scoping Review. Healthcare. 2020;8(2):143. doi:10.3390/healthcare8020143

43. Alfadl AA, Alrasheedy AA, Alhassun MS. Evaluation of medication counseling practice at community pharmacies in Qassim region, Saudi Arabia. Saudi Pharm J. 2018;26(2):258-62. doi:10.1016/j.jsps.2017.12.002

44. Jacobi J. Clinical Pharmacists: Practitioners Who Are Essential Members of Your Clinical Care Team. Rev Méd Clín Las Condes. 2016;27(5):571-7. doi:10.1016/j.rmclc.2016.09.002

45. Boostani K, Noshad H, Farnood F, Rezabee H, Teimouri S, Entezari-Maleki T, et al. Detection and Management of Common Medication Errors in Internal Medicine Wards: Impact on Medication Costs and Patient Care. Adv Pharm Bull. 2019;9(1):174-9. doi:10.15171/apb.2019.020

46. Alqenae FA, Steinke D, Keers RN. Prevalence and Nature of Medication Errors and Medication-Related Harm Following Discharge from Hospital to Community Settings: A Systematic Review. DrugSaf. 2020;43(6):517-37. doi:10.1007/s40264-020-00918-3

47. Keers RN, Williams SD, Cooke J, Ashcroft DM. Causes of Medication Administration Errors in Hospitals: a Systematic Review of Quantitative and Qualitative Evidence. Drug Saf. 2013;36(11):1045-67. doi:10.1007/s40264-013-0090-2

48. Cheragi MA, Manoocheri H, Mohammadnejad E, Ehsani SR. Types and causes of medication errors from nurse's viewpoint. Iran J Nurs Midwifery Res. 2013;18(3):228-31.

49. Zhou S, Kang H, Yao B, Gong Y. Analyzing Medication Error Reports in Clinical Settings: An Automated Pipeline Approach. AMIA Annu Symp Proc. 2018;2018:1611-20.
50. Tan X, Gu D, Lin X, Fang H, Asakawa T. Investigation of the characteristics of medication errors and adverse drug reactions using pharmacovigilance data in China. Saudi Pharm J. 2020;28(10):1190-6. doi:10.1016/j.jsps.2020.08.008

51. Jin J, Sklar GE, Oh VMS, Li SC. Factors affecting therapeutic compliance: A review from the patient's perspective. Ther Clin Risk Manag. 2008;4(1):269-86. doi:10.2147/tcrm.s1458

52. Mishra SI, Gioia D, Childress S, Barnet B, Webster RL. Adherence to Medication Regimens among LowIncome Patients with Multiple Comorbid Chronic Conditions. Health Soc Work. 2011;36(4):249-58. doi:10.1093/hsw/36.4.249

53. de Magalhães AMM, de Moura GMSS, Pasin SS, Funcke LB, Pardal BM, Kreling A. The medication process, workload and patient safety in inpatient units. Rev Esc Enferm USP. 2015;49:43-50. doi:10.1590/s0080-623420150000700007

54. McLellan AT. Substance Misuse and Substance use Disorders: Why do they Matter in Healthcare? Trans Am Clin Climatol Assoc. 2017;128:112-30.

55. Lavan AH, Gallagher P. Predicting risk of adverse drug reactions in older adults. Ther Adv Drug Saf. 2016;7(1):11-22. doi:10.1177/2042098615615472

56. Hosain F, Lee J, Ata A, Bhullar RK, Chang AK. Physician Renewal of Chronically Prescribed Controlled Substances Based on Urine Drug Test Results. J Prim Care Community Health. 2019;10:2150132719883632. doi:10.1177/2150132719883632

57. Misasi P, Keebler JR. Medication safety in emergency medical services: approaching an evidence-based method of verification to reduce errors. Ther Adv Drug Saf. 2019;10:2042098618821916. doi:10.1177/2042098618821916

58. Velo GP, Minuz P. Medication errors: prescribing faults and prescription errors. Br J Clin Pharmacol. 2009;67(6):624-8. doi:10.1111/j.13652125.2009.03425.x

59. Bondesson A, Eriksson T, Kragh A, Holmdahl L, Midlöv P, Höglund P. In-hospital medication reviews reduce unidentified drug-related problems. Eur JClin Pharmacol. 2013;69(3):647-55. doi:10.1007/s00228012-1368-5 
60. Strand LM, Morley PC, Cipolle RJ, Ramsey R, Lamsam GD. Drug-related problems: their structure and function. DICP. 1990;24(11):1093-7. doi:10.1177/106002809002401114

61. Garin N, Sole N, Lucas B, Matas L, Moras D, RodrigoTroyano A, et al. Drug related problems in clinical practice: a cross-sectional study on their prevalence, risk factors and associated pharmaceutical interventions. Sci Rep. 2021;11:883. doi:10.1038/s41598-020-80560-2

62. Westerlund T, Marklund B. Community pharmacy and primary health care in Sweden - at a crossroads. Pharm Pract. 2020;18(2):1927. doi:10.18549/PharmPract.2020.2.1927

63. Giardina C, Cutroneo PM, Mocciaro E, Russo GT, Mandraffino G, Basile G, et al. Adverse Drug Reactions in Hospitalized Patients: Results of the FORWARD (Facilitation of Reporting in Hospital Ward) Study. Front Pharmacol. 2018;9:350. doi:10.3389/fphar.2018.00350

64. Molina-Mula J, Gallo-Estrada J. Impact of NursePatient Relationship on Quality of Care and Patient Autonomy in Decision-Making. Int J Environ Res Public Health. 2020;17(3):835. doi:10.3390/ijerph17030835

65. Bramer WM, de Jonge GB, Rethlefsen ML, Mast F, Kleijnen J. A systematic approach to searching: an efficient and complete method to develop literature searches. J Med Libr Assoc. 2018;106(4):531-41. doi:10.5195/jmla.2018.283

66. Green BN, Johnson CD. Interprofessional collaboration in research, education, and clinical practice: working together for a better future. J Chiropr Educ. 2015;29(1):1-10. doi:10.7899/JCE-14-36

67. Aubert CE, Streit S, Da Costa BR, Collet TH, Cornuz J, Gaspoz JM, et al. Polypharmacy and specific comorbidities in university primary care settings. Eur J Intern Med. 2016;35:35-42. doi:10.1016/j.jejim.2016.05.022

68. Payne RA, Abel GA, Avery AJ, Mercer SW, Roland MO. Is polypharmacy always hazardous? A retrospective cohort analysis using linked electronic health records from primary and secondary care. $\mathrm{Br} \mathrm{J}$ Clin Pharmacol. 2014;77(6):1073-82. doi:10.1111/bcp.12292

69. Hailu BY, Berhe DF, Gudina EK, Gidey K, Getachew M. Drug related problems in admitted geriatric patients: the impact of clinical pharmacist interventions. BMC Geriatr. 2020;20:13. doi:10.1186/s12877-020-1413-7

70. Paisansirikul A, Ketprayoon A, Ittiwattanakul W, Petchlorlian A. Prevalence and Associated Factors of Drug-Related Problems Among Older People: A Cross-Sectional Study at King Chulalongkorn Memorial Hospital in Bangkok. Drugs Real World Outcomes. 2021;8(1):73-84. doi:10.1007/s40801-02000219-2

71. Ramananth KV, Nedumbaili S. Assessment of Medication-Related Problems in Geriatric Patients of a Rural Tertiary Care Hospital. J Young Pharm. 2012;4(4):273-8. doi:10.4103/0975-1483.104372

72. Nobili A, Garattini S, Mannucci PM. Multiple diseases and polypharmacy in the elderly: challenges for the internist of the third millennium. J Comorb. 2011;1:28-44. doi:10.15256/joc.2011.1.4

73. Kurt M, Akdeniz M, Kavukcu E. Assessment of Comorbidity and Use of Prescription and Nonprescription Drugs in Patients Above 65 Years Attending Family Medicine Outpatient Clinics. Gerontol Geriatr Med. 2019;5:2333721419874274. doi:10.1177/2333721419874274

74. Peterson C, Gustafsson M. Characterisation of DrugRelated Problems and Associated Factors at a Clinical Pharmacist Service-Naïve Hospital in Northern Sweden. Drugs Real World Outcomes. 2017;4(2):97107. doi:10.1007/s40801-017-0108-7

75. Gerber W, Steyn JD, Kotzé AF, Hamman JH. Beneficial Pharmacokinetic Drug Interactions: A Tool to Improve the Bioavailability of Poorly Permeable Drugs. $\quad$ Pharmaceutics. 2018;10(3):106. doi:10.3390/pharmaceutics10030106

76. Palleria C, Di Paolo A, Giofrè C, Caglioti C, Leuzzi G, Siniscalchi A, et al. Pharmacokinetic drug-drug interaction and their implication in clinical management. J Res Med Sci. 2013;18(7):601-10.

77. Svensson EM, Acharya C, Clauson B, Dooley KE, Karlsson MO. Pharmacokinetic Interactions for Drugs with a Long Half-Life-Evidence for the Need of Model-Based Analysis. AAPS J. 2016;18(1):171-9. doi:10.1208/s12248-015-9829-2

78. Cascorbi I. Drug Interactions-Principles, Examples and Clinical Consequences. Dtsch Arztebl Int. 2012;109(33-34):546-56. doi:10.3238/arztebl.2012.0546 
79. De Rose DU, Cairoli S, Dionisi M, Santisi A, Massenzi L, Goffredo BM, et al. Therapeutic Drug Monitoring Is a Feasible Tool to Personalize Drug Administration in Neonates Using New Techniques: An Overview on the Pharmacokinetics and Pharmacodynamics in Neonatal Age. Int J Mol Sci. 2020;21(16):5898. doi:10.3390/ijms21165898

80. McDonagh EM, Boukouvala S, Aklillu E, Hein DW, Altman RB, Klein TE. PharmGKB Summary: Very Important Pharmacogene information for Nacetyltransferase 2. Pharmacogenet Genomics. 2014;24(8):409-25.

doi:10.1097/FPC.0000000000000062

81. Jacob S, Nair AB. An Updated Overview on Therapeutic Drug Monitoring of Recent Antiepileptic Drugs. $\quad$ Drugs R\&D. 2016;16:303-16. doi:10.1007/s40268-016-0148-6

82. Tobias JD, Leder M. Procedural sedation: A review of sedative agents, monitoring, and management of complications. Saudi J Anaesth. 2011;5(4):395-410. doi:10.4103/1658-354X.87270

83. Shanika LGT, Wijekoon CN, Jayamanne S, Coombes J, Coombes I, Mamunuwa N, et al. Acceptance and attitudes of healthcare staff towards the introduction of clinical pharmacy service: a descriptive crosssectional study from a tertiary care hospital in Sri Lanka. BMC Health Serv Res. 2017;17:46. doi:10.1186/s12913-017-2001-1

84. Ates HC, Roberts JA, Lipman J, Cass AEG, Urban GA, Dincer C. On-Site Therapeutic Drug Monitoring. Trends Biotechnol. 2020;38(11):1262-77. doi:10.1016/j.tibtech.2020.03.001

85. Feghali M, Venkataraman R, Caritis S. Pharmacokinetics of drugs in pregnancy. Semin Perinatol. doi:10.1053/j.semperi.2015.08.003

86. Johnson-Davis K, Doyle K. Therapeutic Drug Monitoring in Pregnant Patients. Ther Drug Monit. 2020;42(2):172-80. doi:10.1097/FTD.0000000000000709

87. Kristensen N, Nymann C, Konradsen H. Implementing research results in clinical practice- the experiences of healthcare professionals. BMC Health Serv Res. 2016;16:48. doi:10.1186/s12913-016-1292-y

88. Bank L, Jippes M, Scherpbier AJJA, den Rooyen C, Scheele F. How to Get Your Clinical Teaching Team Ready for Curriculum Change: A Practical Guide.
Adv Med Educ Pract. 2019;10:979-86. doi:10.2147/AMEP.S211958

89. Childers CP, Maggard-Gibbons M. Understanding Costs of Care in the Operating Room. JAMA Surg. 2018;153(4):e176233. doi:10.1001/jamasurg.2017.6233

90. Harper L, Powell J, Pijl EM. An overview of forensic drug testing methods and their suitability for harm reduction point-of-care services. Harm Reduct J. 2017;14:52. doi:10.1186/s12954-017-0179-5

91. Hotchkiss RS, Moldawer LL, Opal SM, Reinhart K, Turnbull IR, Vincent JL. Sepsis and septic shock. Nat Rev Dis Primers. 2016;2:16045. doi:10.1038/nrdp.2016.45

92. Lam WY, Fresco P. Medication Adherence Measures: An Overview. Biomed Res Int. 2015;2015:217047. doi:10.1155/2015/217047

93. Bronkhorst E, Gous AGS, Schellack N. Practice Guidelines for Clinical Pharmacists in Middle to Low Income Countries. Front Pharmacol. 2020;11:978. doi:10.3389/fphar.2020.00978

94. Bawankar RD, Mundhadad R, Wake PS, Kedia AS. Pharmacovigilance and Drug Safety in India - An Unmet Need or Challenge? J Pharmacovigil Pharmacother. 2017;17(5):1-3. doi:10.29011/JPPT124.100024

95. Desai MK. Pharmacovigilance and assessment of drug safety reports during COVID 19. Perspect Clin Res. 2020;11(3):128-31. doi:10.4103/picr.PICR_171_20

96. Vallano A, Cereza G, Pedròs C, Agustí A, Danés I, Aguilera C, et al. Obstacles and solutions for spontaneous reporting of adverse drug reactions in the hospital. Br J Clin Pharmacol. 2005;60(6):653-8. doi:10.1111/j.1365-2125.2005.02504.x

97. Bhattacharya S. The Facts About Penicillin Allergy: A Review. J Adv Pharm Technol Res. 2010;1(1):11-7.

98. Sharif-Askari FS, Sharif-Askari NS, Javadi M, Gholami K. Adverse drug reactions reported to the drug and poison information center of Tehran, Iran. PLoS One. 2017;12(9):e0185450. doi:10.1371/journal.pone.0185450

99. Krähenbühl-Melcher A, Schlienger R, Lampert M, Haschke M, Drewe J, Krähenbühl S. Drug-related problems in hospitals: a review of the recent literature. Drug Saf. 2007;30(5):379-407. doi:10.2165/00002018-200730050-00003 
100. Ranganathan SS, Houghton JE, Davies DP, Routledge PA. The involvement of nurses in reporting suspected adverse drug reactions: experience with the meningococcal vaccination scheme. Br J Clin Pharmacol. 2003;56(6):658-63. doi:10.1046/j.1365-2125.2003.01903.x

101. Barolet D, Benohanian A. Current trends in needlefree jet injection: an update. Clin Cosmet Investig Dermatol. 2018;11:231-38. doi:10.2147/CCID.S162724

102. Ravi AD, Sadhna D, Nagpaal D, Chawla L. Needle free injection technology: A complete insight. Int J Pharm Investig. 2015;5(4):192-9. doi:10.4103/2230973X.167662 